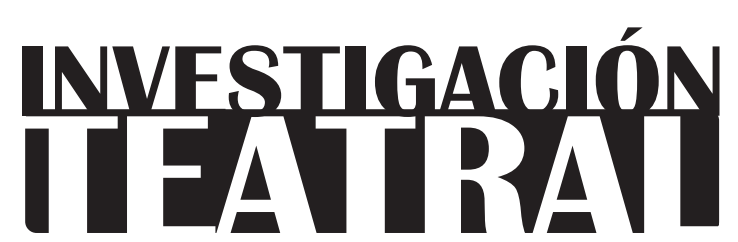

Revista de artes escénicas y performatividad

Vol. 10, Núm. 15

abril-septiembre 2019

Segunda época

ISSN impreso: 1665-8728

ISSN electrónico: 2594-0953

Universidad Veracruzana

\title{
Meyerhold, entre la técnica extracotidiana de inculturación y aculturación. Estudio desde la antropología teatral
}

Sergio Naranjo Velásquez*

\footnotetext{
* Departamento de Artes Escénicas de la Universidad de Caldas, Manizales, Colombia.

e-mail: sergionaranjo13@gmail.com
}

Recibido: 23 de noviembre de 2018

Aceptado: 15 de febrero de 2019 
INVESTIGACIÓNTEATRAL

Revista de artes escénicas y performatividad

Vol. 10, Núm. 15

abril-septiembre 2019
Meyerhold, entre la técnica extracotidiana

de inculturación y aculturación

Sergio Naranjo Velásquez

\section{Meyerhold, entre la técnica extracotidiana de inculturación y aculturación. Estudio desde la antropología teatral}

\section{Resumen}

Este artículo estudia, desde la antropología teatral de Eugenio Barba, si la biomecánica de Meyerhold se basa en una técnica extracotidiana de inculturación o en una técnica extracotidiana de aculturación. Esta investigación permite enlazar concepciones que, a priori, se presentan separadas, demostrando que la técnica extracotidiana inculturada y la técnica extracotidiana aculturada tienen elementos que se relacionan. Aunque parezca paradójico encontrar símiles entre estos conceptos, que tradicionalmente se han considerado "opuestos", se constatan y contrastan de forma indirecta los principios técnicos inculturados y aculturados, que hoy se trabajan desde el punto de vista de la antropología teatral.

Palabras clave: antropología teatral, cuerpo, pre-expresividad, biomecánica.

\section{Meyerhold, between the Extra-quotidian Techniques of Enculturation and Acculturation. A View from Theater Anthropology}

\section{Abstract}

Based on Eugenio Barba's Theater Anthropology, this article examines whether Meyerhold's Biomechanics is based on either of the extra-quotidian techniques of enculturation or acculturation. The purpose is to link these two hitherto separated and even opposite concepts, and to demonstrate that both techniques, as understood in Theater Anthropology, have elements in common.

Keywords: Theater Anthropology, body, pre-expressivity, Biomechanics. 


\section{Meyerhold, entre la técnica extracotidiana de inculturación y aculturación. Estudio desde la antropología teatral ${ }^{1}$}

\section{Técnica extracotidiana de inculturación y aculturación}

$\mathrm{P}$ artiendo del concepto y significado de la antropología teatral, conociendo su estructura y forma de proceder en referencia a la técnica del actor en el campo de la pre-expresividad, este artículo analiza el principio básico que sustenta la presencia del actor sobre el escenario que, según dicha disciplina, es la diferenciación entre técnica cotidiana y técnica extracotidiana. Se trata de uno de los aspectos más complejos y criticados en la propuesta antropológica de Eugenio Barba.

En su libro Hacia un tercer teatro, Ian Watson resume el pensamiento de Barba acerca de las técnicas corporales de la vida cotidiana, diciendo que éstas equivalen simplemente a "acciones físicas automatizadas". En efecto, al referirse a las técnicas cotidianas, Barba afirma sumariamente que los comportamientos automatizados pueden considerarse habituales, y no se detiene a explicitar las cualidades que puede presentar una técnica cotidiana. En vez de ello, su antropología teatral se centra en las técnicas extracotidianas del cuerpo, entendidas como técnicas con fines primariamente escénicos. En tal contexto, lo importante radica en abordar aquellas técnicas que traspasan los condicionamientos cotidianos del cuerpo, visualizando aquellos movimientos que son mucho más complejos (de una dificultosa artificialidad) y amplifican la presencia de un cuerpo en una situación de

1 Este artículo ha sido escrito a partir del capítulo v de mi tesis doctoral, titulada "La técnica extracotidiana en la creación del cuerpo escénico: inculturación y aculturación, análisis y modelo pedagógico", dirigida por el doctor Francesc Xavier Escribano López. 
representación, donde el gasto energético es el máximo en comparación con el que utilizan las acciones cotidianas. A partir de tales movimientos y acciones, Barba elabora su teoría de las técnicas extracotidianas.

Dicha teoría, no obstante, deja entrever un nuevo matiz al referirse a la existencia de dos puntos de partida para trabajar los comportamientos extracotidianos, es decir, la lógica de la inculturación, frente a la lógica de la aculturación:

Una es un punto de salida que sigue la lógica del comportamiento cotidiano, sigue la lógica de la inculturación para llegar a una dilatación de las energías. Es lo que se encuentra como el método o el punto de salida dominante en la cultura teatral occidental, es el método de Stanislavski organizado. Es decir, crea sobre el escenario una presencia que toma como punto de salida la coherencia de la vida cotidiana, pero no la imita sino que reconstruye los procesos que la caracterizan de manera dilatada y consecuente (Barba, "La conferencia de Santiago" 89).

La técnica de la aculturación, en cambio, busca crear una otra cultura física, la modelación del cuerpo desde el exterior, que no responde ya a la lógica de la técnica cotidiana ni al camino de la inculturación:

La técnica de aculturación vuelve artificial (o 'estiliza', como se dice a menudo) el comportamiento del actor-bailarín, pero al mismo tiempo crea otra calidad de energía. Todos hemos tenido esa experiencia al ver a un actor clásico hindú o japonés, a un bailarín moderno o a un mimo. Es fascinante hasta qué punto han logrado modificar su 'naturaleza', transformándola en ligereza como en el ballet clásico, o en el vigor de un árbol en la danza moderna. La técnica de aculturación es distorsión de la apariencia para recrearla sensorialmente más real, fresca y sorprendente (Barba y Savarese 279).

Vistos los conceptos de técnicas extracotidianas de inculturación y aculturación, a continuación pasamos a estudiar si la biomecánica de Meyerhold se basa en una u otra técnica. 


\title{
Vsevolod Meyerhold y la corriente simbolista
}

\author{
"Si la punta de la nariz trabaja, todo el cuerpo también \\ trabaja".
}

Meyerhold (citado en Law y Gordon 135)

Vsevolod Meyerhold (1874-1940)² fue un actor, director y teórico teatral que impulsó el antinaturalismo, en contraposición al naturalismo que promovía Stanislavski. ${ }^{3}$ En 1898 había trabajado con él en el Teatro de Arte de Moscú (TAM), donde conoció de primera mano las investigaciones del método stanislavskiano (en aquel momento transitaban por su primera etapa). Precisamente, su inconformidad con el entrenamiento actoral naturalista y su fuerte atracción por la corriente simbolista lo conducen a abandonar el TAM en 1902, decidido a probar nuevos caminos ${ }^{4}$ que desembocarían en su propia teoría y el lugar destacado que ésta ha tenido para la historia teatral del siglo xx.

Tanto la formación actoral, como la relación con el espectador y el carácter social (tercer teatro), son los principios fundamentales en las teorías de Meyerhold, los cuales pueden encontrar eco en los postulados teórico-metodológicos de la antropología teatral. Eugenio Barba siempre ha destacado el papel que tuvo Meyerhold en la creación de su propia teoría: "A continuación me dirigiré a los muertos, a los libros-fuentes de la 'ciencia' del teatro. Sobre mi escritorio están Stanislavski, Meyerhold y Brecht" (Barba, Más allá de las islas 129).

2 Meyerhold, en 1939, fue detenido y torturado por el Partido Comunista de Stalin; en febrero de 1940 es acusado de trotskista, espía británico y japonés, lo cual desemboca en su fusilamiento.

3 Galina Tolmacheva, quien fuera discípula de Stanislavski, comenta sobre esta aparente oposición: "Psicotécnica y Biomecánica. Stanislavski y Meyerhold ¿Qué diferencia y qué semejanza! Dos extremos, dos polos tan opuestos como parecidos. Ambos parten de la técnica pura. Uno se consagra al minucioso trabajo analítico en el campo de las posibilidades psíquicas del ejecutante, y aspira a llegar al perfeccionamiento artístico mediante el desarrollo y entrenamiento casi científico de la psiquis del actor; el otro hace lo mismo en cuanto a las posibilidades físicas, y procura lograr la misma perfección desarrollando casi científicamente las condiciones físicas del intérprete" (Tolmacheva 367).

4 En esta época empiezan a aparecer nuevas corrientes estéticas que pretenden romper con la estructura naturalista (la ópera y el ballet son pioneros en este cambio), siendo que el "principal responsable de estas innovaciones era un movimiento, 'El mundo del Arte', con una revista literaria del mismo nombre fundada en 1898. Esta revista tenía como programa desafiar el academicismo y el naturalismo en iniciar la lucha contra la estética materialista o de intención social. Pero lo más importante no fue lo que negó, sino lo que promocionó y propagó. Dio un gran impulso a todas las artes visuales, iniciando el movimiento de las artes gráficas y el grabado" (Meyerhold, Teoría Teatral 11). 
El "nuevo teatro" o teatro de "convención consciente" -como lo llamó Meyerhold, interesado en que "la plástica no correspondiera a las palabras"-, generó un trabajo de estilización: "Este concepto nace de la necesidad de sacar a los actores de la anarquía del teatro naturalista para llevarlos a una toma de conciencia en cuanto a los principios organizativos de un teatro de realismo convencional" (Meyerhold, El actor 165).

El procedimiento teatral que Meyerhold lleva a cabo, persigue como objeto estético una puesta en escena de carácter artificial: "una dramaturgia y una puesta en escena que no oculten los procedimientos de construcción y de funcionamiento teatral” (Pavis 356). Esta nueva concepción difiere de la consigna del teatro naturalista; sin embargo, Meyerhold matiza su separación del realismo ilustrado, logrando por medio de la abstracción estilizar la realidad.

Meyerhold encontró en el simbolismo ${ }^{5}$ equivalentes plásticos con los cuales comunicar la realidad; se interesaba por una composición plástica que no concordase con las palabras, gestos corporales y texto hablado. Para Meyerhold, cada uno de estos elementos puede tener su propio ritmo y en ocasiones aparecer desligado de los otros.

\section{Teatro de la convención consciente}

Gordon Craig, en 1910, ya se refería al simbolismo como un bien sensato, ordenado y universal," "porque el simbolismo se encuentra en las raíces no sólo del arte, sino de la vida misma; es sólo por medio de símbolos que la vida se vuelve posible" (286).

5 La corriente simbolista nace a finales del siglo xIX como un movimiento en contraposición al naturalismo y realismo de la época. Para Dan Sperber, "el simbolismo es un segundo modo de acceso a la memoria adoptado cuando fracasa el primero y que permite la interpretación de la información. Así, podríamos suponer que la cognición en el hombre es el primer mecanismo adaptativo. Por ejemplo, cuando una serie de acontecimientos o datos se presentan sin una causa primera, se elabora una construcción mental simbólica: para el primitivo, ésta remitirá a los espíritus y para el científico, a ciertos principios axiomáticos" (15). Con esto, Sperber da entender que el proceso cognitivo que realiza nuestra mente permite alcanzar, por medio del simbolismo, un aprendizaje y una forma de expresión liberadora del ser humano.

6 Gordon Craig, en referencia a que el símbolo es utilizado universalmente, da los siguientes ejemplos: "Las letras del alfabeto son símbolos que empleamos cotidianamente. Los números son símbolos, y la química y la matemática los utilizan. Todas las monedas del mundo son símbolos; y los hombres de negocios tienen confianza en ellos. La corona y el cetro de los reyes, así como la tiara de los papas son símbolos. Las obras de los pintores y de los poetas, de los arquitectos y los escultores, están llenas de simbolismo; los chinos, los egipcios, los griegos, los romanos y los artistas modernos han entendido y apreciado en su valor al símbolo" (286). 
Para utilizar todos estos símbolos en escena, deben existir, en primera instancia, una serie de convenciones ${ }^{7}$ tanto para el actor como para el espectador; son como las reglas de un juego: se requiere consciencia sobre ellas y que sean respetadas. Lo que se presenta en el juego teatral ya no es observado como algo real (naturalista), sino como una ficción ${ }^{8}$ que está elaborada por medio de signos, donde predomina el cuerpo con su diseño de movimiento, plástica y musicalidad.

Para este nuevo teatro:

Por fin, la técnica convencional supone en el teatro, después del autor, escenógrafo y actor, al cuarto creador: el espectador. El teatro de convención elabora puestas en escena donde el espectador, con su imaginación, debe completar de manera creativa el dibujo de las ilusiones dadas allí en escena (Meyerhold, Écrits sur le Théâtre 116).

El espectador de este teatro deja de ser un ente estático; ahora se le anima a pensar y a discutir, ya no se trata sólo de una sensibilidad emotiva sino de una sensibilidad sensorial. Según Barba: "Meyerhold quiere provocar en el espectador un reflejo emocional que no pasa necesariamente a través del aspecto intelectual, sino que se basa en la sensibilidad sensorial y cinestésica" (Barba y Savarese 179), algo con lo que su antropología teatral está de acuerdo, al considerar que un mismo espectáculo puede convertirse en una auténtica "expedición antropológica". Se crea una experiencia tanto para el actor como para el espectador, sin que esto signifique que tiene que ser la misma para los dos. ${ }^{9}$

7 Bertold Brecht, años más tarde, también crearía una serie de convenciones para crear su conocido efecto de distanciamiento, con el cual se oponía a la tendencia de los espectadores a identificarse con los personajes, sin llegar a tener alguna reflexión crítica.

8 Comenta Meyerhold, en 1907, que "en el teatro de la convención consciente, el espectador no olvida un instante que tiene delante a un actor que representa, como el actor no olvida un instante que se trata de colores, de tela, de pinceles y, sin embargo, se percibe un sentimiento de la vida sublimado, depurado. Sucede, a menudo, que, cuanto más parece un cuadro, más potente es el sentimiento de la vida" (Meyerhold, Teoría Teatral 54). Es un teatro que lucha contra la ilusión que quería plasmar a toda costa el teatro naturalista.

9 Eugenio Barba, en su artículo "Abuelos y Huérfanos", habla sobre la perspicacia que deben tener tanto el espectador como el actor: "No quiere decir que uno y otro perciban la misma experiencia realizando la acción teatral o asistiendo a ella. Un actor puede realizar una exploración personal y buscar un sentido, en y con el microcosmos de su cuerpo-mente, que permanece independiente en relación con el sentido y la exploración que realiza el espectador asistiendo al espectáculo" (Barba y Savarese 89). 


\section{Cotidianidad grotesca}

Para cambiar la percepción del espectador y del actor, Meyerhold recurre al género grotesco $^{10}$ que ya estaba instaurado en la literatura, la música y las artes plásticas. En efecto, encuentra en el género una nueva forma de observar la vida cotidiana, de profundizarla por medio del contraste, según lo exponía en 1912:

Al grotesco le está permitido aproximarse de modo insólito a la vida cotidiana. El grotesco permite precisamente la vida cotidiana, cesando de representarse sólo lo que es habitual. En la vida, además de lo que vemos, hay también un vastísimo sector inexplorado. El grotesco, buscando lo sobrenatural, junta en síntesis la escénica de los contrarios, crea un cuadro del fenómeno e induce al espectador a la tentativa de resolver el enigma de lo incomprensible (Meyerhold, Meyerhold: Textos Teóricos 195).

Este nuevo enfoque de lo cotidiano, refleja que Meyerhold -al igual que Stanislavski- tuvo presentes en su trabajo teatral a los elementos de la vida cotidiana; la diferencia reside en que Meyerhold lo hacía a través de una estilización de la realidad (la forma exterior en la que se dilata el cuerpo aculturado), mientras que Stanislavski refleja la vida cotidiana como un efecto de ilusión, que se inicia con la dilatación de la mente sobre el cuerpo inculturado:

Para Meyerhold, el grotesco constituye un 'nuevo enfoque de lo cotidiano', el grotesco 'profundiza lo cotidiano... El grotesco está regido así por la ley de la disonancia. Ésta permite constituir una suerte de coincidentia oppositorum que se convierte en el principio creador y filosófico del teatro, el soporte de la visión de mundo de Meyerhold, quien aspira a una 'belleza armoniosa' que asegure la disonancia. Por lo tanto, justamente gracias al grotesco $^{11}$ y a esta belleza armoniosa, el cotidiano será vencido en el cotidiano (De Toro 156-57).

10 El género grotesco, aplicado al teatro, la dramaturgia y la presentación escénica, tiene la intención de "conservar su esencial función de principio de deformación, con el suplemento por si fuere poco de un enorme sentido de lo concreto y del detalle naturalista" (Pavis 227).

11 En su escrito "El grotesco como forma escénica" de 1912, Meyerhold recurre a un ejemplo para mostrar cómo la vida puede verse con otra óptica a través de los contrastes: "En un día otoñal, lluvioso, por la calle se alarga un cortejo fúnebre. Por la actitud que adoptan las gentes que marchan tras el féretro, se ve una profunda condolencia; de repente, el viento arranca el sombrero de la cabeza de uno de los apenados acompañantes. Se inclina a recogerlo, pero el viento se lo lleva de una parte a otra. Cada salto del compungido señor tras el sombrero obliga a su cuerpo a contorsiones tan cómicas, que una mano diabólica transforma de repente el tétrico cortejo fúnebre en multitud festiva. ¡Ojala pudiésemos lograr este efecto sobre el escenario! Contraste" (Meyerhold: Textos Teóricos 195). 
El efecto de ilusión de la vida cotidiana buscado por Stanislavski, y el efecto de ficción de la vida cotidiana de Meyerhold, muestran, desde el punto de vista de los resultados, una oposición; sin embargo, desde el punto de vista pre-expresivo no representan objetivos tan opuestos: la técnica extracotidiana se hace visible en uno y otro caso, así parta de la inculturación, o bien, del sentido aculturado.

\section{Pre-expresividad biomecánica}

Para alcanzar esta cotidianidad grotesca o "realismo estilizado", Meyerhold, en 1914, empieza a trabajar el cuerpo a nivel pre-expresivo: " ¿Cómo debe moverse el actor en escena, cómo debe incidir aquel 'dibujo de movimientos' que concretan la relación actor-espectador a nivel sensorial, antes que a nivel intelectual y emotivo?" (Barba y Savarese 180).

Con este programa de estudio, ${ }^{12}$ que en 1922 presenta sus resultados más recientes, Meyerhold hace el tránsito del "teatro de convención consciente" al método de la biomecánica, la cual fue definida así: "La ley fundamental de la biomecánica es muy sencilla: el cuerpo entero participa en cada uno de nuestros movimientos. A continuación, no hay que hacer más que realizar estudios y una serie de ejercicios de perfeccionamiento" (Meyerhold, El actor sobre la escena 111).

Este interés por individualizar y perfeccionar el movimiento es extrapolado al comportamiento cotidiano de los obreros en su trabajo:

Examinando el trabajo de un obrero experto, encontramos en sus movimientos: 1) ausencia de desplazamientos superfluos, improductivos; 2) ritmo; 3) determinación del centro justo de gravedad del propio cuerpo; 4) resistencia. Los movimientos fundados sobre estas bases se distinguen por su carácter de 'danza'; el trabajo de un obrero experto recuerda siempre a la danza, y en este punto bordea los límites del arte (Meyerhold, Meyerhold: Textos Teóricos 230).

Meyerhold plantea que la técnica que utiliza un obrero en su trabajo habitual ha sido perfeccionada por medio de la disciplina y la repetición en el tiempo, a través de lo cual deviene un experto, generando una "segunda técnica" distinta a la cotidiana. También nosotros somos expertos en la esfera del comportamiento cotidiano, como implicaba el antropólogo

12 Aparte de la técnica en movimiento que se daba en su programa de estudio, Meyerhold hizo estudiar a sus actores Commedia dell'Arte, teatro de los siglos XVIII y xIX, teatro oriental, circo, danza, música, así como deportes como atletismo ligero, esgrima, tenis, lanzamiento de disco y navegación a vela. 
Marcel Mauss ${ }^{13}$ al hablar de las técnicas del cuerpo. Sin embargo, lo que le interesa a Meyerhold es el proceso físico por el que pasa un obrero para volverse experto en su ocupación; ahí encuentra la justificación para dar a entender que el trabajo del actor también está condicionado por el adiestramiento de sus bases materiales. El cuerpo del intérprete debe tener la capacidad de utilizar de forma correcta sus medios expresivos, es decir, adquirir una "segunda técnica" que le permita instantáneamente ejecutar las órdenes del director y del autor sobre su biomecánica:

El actor comprende en sí mismo tanto a quien organiza como a lo que debe ser organizado (es decir, el artista es el material). La fórmula del actor consistirá en la siguiente expresión: $\mathrm{N}=\mathrm{A} 1+\mathrm{A} 2$, siendo $\mathrm{N}$ el actor, A1 el constructor -que formula mentalmente y transmite las órdenes para la realización de la tarea-, y A2 el cuerpo del actor, el ejecutor que realiza la idea del constructor A1 (ibídem).

Lo interesante de la cita anterior es constatar la urgencia, por parte de Meyerhold, de darle a sus estudios experimentales una base científica, inspirado en el sistema del taylorismo ${ }^{14}$ de Frederick Winslow, la reflexología ${ }^{15}$ de Iván Petrovich Pavlov y la teoría de la emoción ${ }^{16}$ de James-Lange. Meyerhold no sólo refiere al camino físico inconsciente, sino que se inte-

13 "Hablo de técnicas corporales porque se puede hacer la teoría de la técnica de los cuerpos partiendo de un estudio, de una exposición, de una simple y pura descripción de las técnicas corporales. Con esa palabra quiero expresar la forma en que los hombres, sociedad por sociedad, hacen uso de su cuerpo en una forma tradicional" (Mauss 337).

14 El taylorismo fue un método de organización del trabajo creado por el ingeniero Frederick Winslow Taylor (1856-1915), con la intención de aumentar la productividad por medio de la máxima división de tareas, en las cuales cada trabajador se especializa y así controla estrictamente el tiempo para la realización de dicha tarea. Meyerhold encontró en estos movimientos especializados una economía del cuerpo que se plasmaban como movimientos rítmicos y fluidos, que permiten tener control sobre el cuerpo; eso mismo es lo que le interesa a la biomecánica.

15 La reflexología de Iván Petrovich Pavlov (1949-1936) es el nombre dado a su escuela de psicología en Rusia. Los estudios de esta escuela tienen una estrecha relación con los procesos fisiológicos; en síntesis, reducen los procesos mentales y psicológicos a procesos fisiológicos, proponiendo un orden diferente de intervención en el cuerpo-mente.

16 Conocida como la teoría de James-Lange -ya que la formulación de las hipótesis de William James y Carl Lang se produjeron en la misma época con resultados similares-, ésta interpreta que, provocando una determinada reacción fisiológica, se produce también una emoción. Ejemplo: el circuito estímulo - cambios fisiológicos - corteza cerebral - emoción. Esta forma diferente de intervenir en el cuerpo-mente, también le dio a Meyerhold un impulso para focalizar aspectos físicos que repercuten en los mentales. 
resa también por los aspectos psicológicos o mentales que, para él, pueden ser estudiados por medio de las leyes de la mecánica.

El punto de partida de su trabajo, a diferencia de Stanislavski, consistía en comenzar por el exterior para luego conectar con el interior: no río porque tenga alegría, sino que tengo alegría porque río. Según Picon-Vallin, ${ }^{17}$ en la biomecánica de Meyerhold:

Todo acto físico se pone en marcha por un proceso nervioso, y toda acción puede tener por respuesta una excitación. El proceso que une la excitación a una respuesta de movimiento es un proceso nervioso, por tanto psicológico; el comportamiento humano es visto como una serie de reflejos naturales y condicionados, pues el sistema nervioso responde en todo momento a las oscilaciones-excitaciones del mundo exterior o de su cuerpo mismo (Picon-Vallin, Meyerhold 106).

Aquí, cada acción hace partícipe al cuerpo entero, mientras que en la técnica cotidiana sólo una parte del cuerpo participa. Recordemos que esta última trabaja por la ley del mínimo esfuerzo, mientras que en las técnicas extracotidianas pasa lo contrario: los ejercicios que realiza un actor biomecánico están destinados para quien hace teatro y no para el punto de vista de los espectadores; trabajan en el nivel pre-expresivo y no se restringen a presupuestos físicos, sino también a una forma de pensar en movimiento.

\section{Otkas, posyl, tormos y stoika: acción biomecánica extracotidiana aculturada}

Según Borja Ruiz, el actor biomecánico sintetiza su interpretación en una partitura de movimiento, que incorpora tanto aspectos internos como externos con una particular matización en cada caso: "En la biomecánica, esta partitura, esta mecánica, por muy establecida que esté, debe cobrar vida, debe jugarse, hacerse flexible, de otro modo la interpretación queda vacía, predecible, robotizada" (125).

Meyerhold trabaja la partitura de acción a través de una aculturización del cuerpo, una codificación que el actor compone en cuatro fases: otkas, posyl, tormos y stoika. Éstas visualizan principios recurrentes en las leyes ${ }^{18}$ pre-expresivas de la antropología teatral de Eugenio Barba.

17 Beatrice Picon-Vallin es una de las mayores especialistas sobre Vsevolod Meyerhold. Ha traducido la obra completa del autor y trabaja en el laboratorio de investigación en las Artes Escénica (Centre National de la Recherche Scientifique) de París.

18 Según Barba, entre los principios recurrentes que pueden encontrarse a través de diferentes tradiciones 
El otkas ${ }^{19}$ es un principio de la biomecánica, donde cada acción que realiza un actor debe estar antecedida por un movimiento en la dirección contraria; es el ante-impulso que prepara al ejecutante para realizar una determinada acción: inclinarse para brincar, girar hacia la derecha para ir hacia la izquierda, desplazarse hacia atrás para ir hacia delante, etcétera. Barba utiliza este concepto de Meyerhold para referirse a la ley de oposición; ${ }^{20}$ el actor ocupa en este caso una técnica extracotidiana estilizada, donde se hace visible la complejidad del diseño.

A su vez, el otkas (rechazo) es el ante-impulso para ejecutar la acción principal llamada posyl ${ }^{21}$ (envío), la cual permite dibujar con el cuerpo la trayectoria de la acción en el espacio, finalizando controladamente a través del $\operatorname{tormos}^{22}$ (freno). Una vez finalizada la acción, el tormos puede dar pie a que el siguiente movimiento se convierta, ya sea en un nuevo otkas o ante-impulso, o bien en una stoika $a^{23}$ (retención), en donde la energía de la acción queda en contención dinámica. En la antropología teatral se diría que la acción tiene sat.

Este sistema de Meyerhold considera múltiples ciclos otkas-posyl-tormos-stoika, los cuales permiten transitar a nuevas acciones y constituyen "la sístole y diástole que mantiene el pulso rítmico de las acciones del actor biomecánico" (Ruiz 127).

escénicas de Oriente y Occidente, se encuentran tres leyes: la alteración del equilibrio, la oposición, y la ley de la no-coherencia coherente.

19 Palabra rusa que significa "rechazo". Según Picon-Vallin, el concepto de otkas es esencial en la biomecánica: "Enunciado en 1914 en el estudio de San Petersburgo, es contemporáneamente definido como un elemento de segmentación de la línea principal de la acción (separación respecto al movimiento precedente [...]) y como un movimiento en contrasentido, que se opone a la dirección del movimiento [...]" (Picon-Vallin, Il lavoro dell'attore 104-105).

20 En la ley de la oposición, el actor activa todo su sistema interno de percepción por medio de movimientos sinuosos, nuevas tensiones se hacen latentes. Barba afirma que la danza de las oposiciones se baila en el cuerpo, antes que con el cuerpo.

21 Palabra rusa que significa "enviar". Según Borja Ruiz, el concepto de posyl "en la biomecánica de Meyerhold, es la acción propiamente dicha, que viene precedida por un ante impulso" (127).

22 Palabra rusa que significa "freno": "en la biomecánica de Meyerhold es la parte final en la ejecución de una acción, donde el impulso que lleva se amortigua hasta llegar a una parada" (ibídem).

23 Palabra rusa que significa "retener": "en la biomecánica de Meyerhold describe la parada con la que finaliza una acción” (ibídem). 


\section{Études biomecánicos aculturados}

El ciclo otkas-posyl-tormos-stoika le permite al actor biomecánico no sólo conocer la "economía" de la dinámica de su cuerpo, sino que además es el principio que da forma a las rutinas de ejercicios de mayor complejidad, llamadas études. En ese nivel, la dramaturgia actoral se complejiza aún más, manteniendo presente el trabajo psicofísico. El trabajo mental constituye la manera de estilizar una realidad ya establecida: se apropia de ciertas técnicas cotidianas que, a su vez, al quedar estilizadas, se transforman en técnicas extracotidianas aculturadas.

Según Picon-Vallin, estos ejercicios creados por Meyerhold fueron extraídos de temáticas de la Commedia dell'Arte, el circo, el teatro oriental, la gimnasia, así como de situaciones de la vida cotidiana. Una vez más, Meyerhold encuentra principios recurrentes en otras disciplinas y tradiciones teatrales para extrapolarlos a su propio trabajo, mientras que la lista completa de los 22 études permite constatar que la vida cotidiana es también un motor en la biomecánica:

1. Tiro con arco.

2. Salto sobre la espalda de un compañero y transporte de la carga.

3. Caer, atrapar y lanzar una piedra.

4. Golpe de puñal.

5. La bofetada.

6. Dar la vuelta con la pierna inclinada y de rodillas de un compañero.

7. Juego de los bastones.

8. Lanzar un balón al aire.

9. Lanzar una piedra.

10. Saltar sobre el pecho del compañero.

11. Juego con puñal corto.

12. La cuadrícula.

13. La cuerda.

14. Los caballos.

15. El patinador.

16. Tropezar.

17. El puente.

18. La sierra.

19. La falta.

20. Funerales.

21. El payaso.

22. Salto del cordero" (Picon-Vallin, Meyerhold 111). 


\section{Étude del tiro con arco: principio de equivalencia extracotidiano}

De los 22 études enumerados, se escoge el primero para ser analizado. La acción de tirar una flecha con un arco permite constatar que el actor biomecánico tenía muy presente en su trabajo a la vida cotidiana. Como veremos, Meyerhold estiliza una técnica cotidiana por medio de lo que -en la antropología teatral- se denomina "principio de equivalencia,, será formulado por Barba a partir, precisamente, del trabajo de los grandes reformadores del teatro (especialmente el propio Meyerhold y Stanislavski).

Todos los études (ejercicios) en la biomecánica, empiezan y terminan de una misma forma mediante el dáctilo, que permite marcar el ritmo y tono muscular para el trabajo, poniendo al actor en un estado de preparación física y mental:

a. Se empieza erguido, con los pies paralelos manteniendo una separación igual a la de las caderas y con el peso igualmente distribuido en ambas piernas.

b. Se traslada el peso hacia adelante.

c. A continuación se flexionan las rodillas, originando el impulso.

d. Este impulso se transmite por toda la columna vertebral y por los brazos que, en consecuencia, se levantan.

e. Cuando, siguiendo el impulso que ahora va a favor de la gravedad, éstos se dirigen hacia el suelo, se dan dos palmadas enérgicas: la primera más lenta y amplia, y la segunda más rápida y reducida. Para esta segunda palmada, se vuelve a tomar impulso, tal y como se había hecho previamente pero de forma menos expansiva.

f. El ejercicio finaliza en la misma posición del inicio". (Ruiz 128)

Una vez realizado el dáctilo, el actor pasa a realizar los études ${ }^{25}$ en este caso el de tiro con arco:

24 Con las equivalencias, Barba no pretende radicalizar la oposición entre el cuerpo cotidiano y el cuerpo en representación, sino demostrar cómo ese cuerpo cotidiano es reelaborado, creando tales equivalencias con fines poéticos, es decir, de "representación" y no de mera "presentación".

25 Para realizar los études, Meyerhold tenía muy presente la importancia de la música. En el caso del ejercicio de tiro con arco, utilizaba el Estudio Op. 12 en C menor de Fréderic Chopin. La música le serviría al actor para mantener el ritmo y poder jugar (desde el punto de vista exterior), así como para mantener una intención interior. "Para Meyerhold, el diseño de los movimientos es la condición sine qua non para ser actor. Meyerhold indaga los criterios de esta condición a lo largo de toda su carrera. Le da siempre más autonomía en relación al trabajo sobre el texto, modelando la partitura ya no con el instrumento del pensamiento dramatúrgico, sino a través del saber musical. Su lengua de trabajo está constituida por la terminología musical y por palabras como 'ritmo', 'danza, 'biomecánica, que sustituirán a 'interpretación' y 'perezhivanie"' (Barba, La canoa de papel 195). 
1. El actor realiza dos dáctilos (se marca el ritmo y tono muscular para realizar la acción equivalente a tirar con un arco).

2. Señalando con el brazo hacia abajo, indica que se ha encontrado un arco (ya desde un principio la imaginación toma una parte importante en el étude).

3. Dobla las rodillas lentamente, manteniendo el torso vertical con sus brazos a los lados.

4. Cae al suelo para recoger el arco imaginario.

5. Vuelve a la posición 3 .

6. Sube lentamente, manteniendo el torso recto hasta estar totalmente de pie.

7. Con el brazo izquierdo, señala y observa que hay una presa imaginaria.

8. Realiza una acción de sigilo, contrayendo el cuerpo.

9. Indica, en principio, la acción de utilizar el arco.

10. Realiza un semicírculo con el brazo derecho.

11. Cambia rápido el peso, de nuevo a una posición horizontal, manteniendo el arco.

12. Empieza a estirar la cuerda, lentamente, buscando una tensión.

13. Transfiere el peso a la pierna derecha, extendiendo horizontalmente los brazos con la imagen de estirar un arco y dispara.

14. Vuelve a la posición 12.

15. Toma impulso, buscando una oposición.

16. Voltea y levanta rápidamente ambos brazos hacia arriba, cabeza también arriba, peso sobre el pie izquierdo y lomo arqueado.

17. Realiza el disparo, que incluye un salto hacia arriba.

18. Vuelve nuevamente a la posición inicial y realiza nuevamente un dáctilo.

Al partir de una acción cotidiana y convertirla en una danza muy precisa, Meyerhold estaría utilizando en este étude el principio de equivalencia. Su trabajo pre-expresivo le permite al actor tener conciencia de su cuerpo y dominarlo a través del ciclo de otkas, posyl, tormos, stoika. En definitiva, en esta secuencia se llevan a cabo, mediante una especie de danza, transferencias de peso que involucran un equilibrio precario, motivando así a que la imagen tenga en todo momento un ritmo fluido. Según Barba:

[...] a través de este ejercicio, el alumno comenzaba a comprender por sí mismo, en términos de espacio, cómo adquirir autocontrol físico, desarrollaba elasticidad y equilibrio; se daba cuenta de que el mínimo gesto resonaba a través del cuerpo entero; practicaba el así llamado rechazo (otkas). En este ejercicio el rechazo, es decir, lo que viene antes que el gesto, es la mano que toma la flecha detrás de la espalda. El ejercicio es un ejemplo de una secuencia de acciones que comprende intención, realización y reacción (Barba y Savarese 151). 


\section{Meyerhold intercultural y la antropología teatral}

Gracias a sus precursores, la antropología teatral deriva de otras tradiciones interpretativas del Oriente (de rasgos estilizados) indicaciones útiles para el actor. El trabajo preciso y de carácter intensamente corporal y técnico de tales tradiciones motivó a nuestros maestros a indagar en los principios recurrentes a través de ellas. Desde Meyerhold con el teatro japonés, Antonin Artaud con las danzas balinesas, Beltrot Brecth con el teatro chino, y Grotowski en la India el ver más allá de Occidente ha sido una constante durante el último siglo.

En el desarrollo de su propuesta, Meyerhold llevó a cabo un viaje transcultural, recurriendo tanto a referencias orientales (como el kabuki, el nô, la Ópera de Pekín), como occidentales (Commedia dell'Arte y circo, por ejemplo). Así, encuentra unos principios que retornan, constituyendo claves para que el actor sepa cómo moverse en el escenario. La danza, por ejemplo, ya no es un arte separado del teatro, sino un modo de intervenir dentro del mismo.

En la misma línea, Barba recurre a autores que se dirigen a Oriente para encontrar principios recurrentes en sus respectivas técnicas teatrales, desarrollando una nueva visión que sintetizaría posteriormente en su antropología teatral. Tal vez sea Meyerhold el autor con quien más se identifica: "Jerzy Grotowski, Eugenio Barba, y en algún sentido también Peter Brook, aparecen como el punto de llegada de la tradición que ha sido llamada de los 'directores pedagogos', según la expresión acuñada por Meyerhold” (De Marinis 14).

Meyerhold no se preocupó solamente por la técnica teatral, sino que, en su interés por encontrar esos principios que retornan, propuso el concepto de escenología, en alusión a la ciencia y teoría de la puesta en escena. Se trataría de una ciencia que abarca todos los elementos involucrados en la creación de una puesta en escena (dramaturgia, dirección, actuación y escenografía), como lo hace actualmente también la llamada etnoescenología. ${ }^{26}$

Específicamente en el nivel que precede al drama, como se ha visto, Meyerhold alude a algunos elementos que pueden entenderse mejor con la ayuda de la antropología teatral de Eugenio Barba (posturas inestables, equilibrio y desequilibrio, ley de los contrarios, energía que danza, técnica cotidiana, técnica extracotidiana, aculturación, principios de equivalencia). A su vez, Barba reconoce que: "Los principios del grotesco, es decir, la biomecánica, no fueron suposiciones fortuitas, sino la ingeniosa interpretación de los mismos principios que hoy, a la luz de la antropología teatral, reencontramos en la base del nivel pre-expresivo del actor" (Barba y Savarese 180).

26 La etnoescenología promueve el estudio de las prácticas espectaculares en el mundo entero, tal como lo propone también la antropología teatral, desligándose del etnocentrismo que el teatro europeo tiene como criterio de análisis de otras prácticas espectaculares, ajenas a su cultura. 


\section{Recapitulación y conclusiones}

- El interés de Meyerhold por la plástica y la estilización de la realidad le llevaron a concebir un nuevo teatro de "convención consciente", que en su concepto podía remediar la indisciplina actoral del teatro naturalista, promoviendo la disciplina en un "realismo convencional".

- El grotesco le permitió a Meyerhold aproximarse de forma insólita a la vida cotidiana. La técnica cotidiana se transforma aquí por medio de la exploración de los contrarios, la cual pone en escena un contraste que implica una estilización de la realidad, llevando al espectador a resolver "el enigma de lo incomprensible".

- La biomecánica le permitió al actor adiestrar sus bases materiales por medio de una sinuosa técnica extracotidiana aculturada, tanto en aspectos físicos como psicológicos. Los aspectos mentales son estudiados desde las leyes de la mecánica, donde toda acción hace partícipe al cuerpo entero.

- La partitura mecánica otkas-posyl-tormos-stoika, permitió al actor conocer, controlar y utilizar su cuerpo con una dinámica "económica" (expresada en la fórmula $N=A 1+$ $A 2)$. Desde el punto de vista expresivo, el actor pudo desarrollar con ello una "segunda técnica", diferente a la cotidiana, para poder ejecutar instantáneamente las órdenes del director y del autor. Es por ello -y no porque se implique un menor gasto de energía-, por lo que se habla de "economía".

- Las rutinas de ejercicios llamadas études constatan, desde el punto de vista de nuestra investigación, que Meyerhold estilizó la técnica cotidiana por medio del principio de equivalencia de la antropología teatral. Esta manera de intervenir, indica el camino pre-expresivo de aculturación implicado en la biomecánica.

- La antropología teatral de Eugenio Barba se nutrió de Meyerhold, según lo muestran las siguientes equivalencias conceptuales:

- Equilibrio y desequilibrio = biomecánica.

- Ley de oposiciones = otkas.

- Sat (impulso, energía que danza) $=$ posyl.

- Ley de la omisión = tormos y stoika.

- Técnica cotidiana = convención consciente.

- Técnica extracotidiana aculturada = biomecánica.

- Principios de equivalencia = études y grotesco.

- Principios que retornan $=K a b u k i$, Nô, ópera de Pekín (oriente), + gimnasia, $b a$ llet, Commedia dell'Arte, circo (occidente).

- Pre-expresividad = biomecánica.

- Antropología teatral = escenología. 
Los principios técnicos que visualizó Meyerhold permiten constatar y contrastar los principios que hoy en día se trabajan desde el punto de vista de la antropología teatral, mostrando que el maestro ruso, por medio de una codificación específica del cuerpo (biomecánica), fue capaz de derivar las emociones como un desenlace del flujo externo del movimiento. Se trata de una particular manera de intervenir en la unidad psicosomática del actor, característica de la técnica extracotidiana aculturada.

\section{Fuentes consultadas}

Barba, Eugenio y Nicola Savarese. El arte secreto del actor. $4^{\text {a }}$ ed. Traducido por Raúl Iza, et al. Lima: San Marcos, 2010.

Barba, Eugenio. La canoa de papel. Tratado de Antropología Teatral. Traducido por Rina Skeel. Buenos Aires: Catálogos Editora, 1994.

Barba, Eugenio. "La conferencia de Santiago (Lecture on Theatre Anthropology Given in Santiago, December 1988)". Apuntes de Teatro, núm. 99, 1988, pp. 87-95.

Barba, Eugenio. Más allá de las islas flotantes. Traducido por Toni Cots. Ciudad de México, México: Escenología A.C., 1986.

Craig, Gordon. El arte del teatro. Traducido por M. Margherita Pavía. Ciudad de México: Grupo Editorial Gaceta, 1987.

De Marinis, Marco. La parábola de Grotowski: el secreto del 'novecento' teatral. Traducido por Silvina Diaz, Claudia y Adriana Castagnini. Buenos Aires: Editorial Galerna, 2004.

De Toro, Fernando. Semiótica y teatro latinoamericano. Buenos Aires: Grupo Editorial Galerna / Instituto Internacional de Teoría y Crítica de Teatro Latinoamericano, 1990.

Law, Alma y Mel Gordon. Meyerhold, Eisenstein and Biomechanics: Actor Training in Revolutionary Russia. North Carolina: McFarland, 1996.

Leach, Robert. "Meyerhold and Biomechanics". Actor Training, editado por Alison Hodge. $2^{\mathrm{a}}$ ed. London: Taylor \& Francis e-Library, 2010, pp. 26-42.

Mauss, Marcel. Sociología y antropología. Traducido por Teresa Rubio y Martín Retortillo. Madrid: Editorial Técnos, 1979.

Meyerhold, Vsévolod. Teoría teatral. $9^{a}$ ed. Traducido por Agustín Barreno. Madrid: Editorial Fundamentos, 2013.

Meyerhold, Vsévolod. El actor sobre la escena. $5^{\text {a }}$ ed. Traducido por Enriqueta Bernal López, Noemí Lucero Castillo y Margherita Pavia. Ciudad de México: Escenología, A.C., 2005.

Meyerhold, Vsévolod. Écrits sur le théâtre, tome 1. 9a ed. Traducido por Béatrice Picon-Vallin. Lausana: Editions L'Age D’Homme, 2001. 
Meyerhold, Vsévolod. Meyerhold: Textos teóricos. 2a ed. Traducido por J. Delgado, et al. Madrid: Publicaciones de la Asociación de Directores de Escena de España, 1992.

Pavis, Patrice. Diccionario del teatro: dramaturgia, estética, semiología. Traducido por Jaume Melendres. Buenos Aires: Paidós, 2008.

Picon-Vallin, Béatrice. Meyerhold. Paris: Centre National de la Recherche Scientifique, 1990.

Picon-Vallin, Béatrice. "Il lavoro dell'attore in Mejerchol'd. studi e materiali". Revista Teatro e Storia, vol. 18, 1996, pp. 85-140.

Ruiz, Borja. El arte del actor en el siglo XX. Un recorrido teórico y práctico por las vanguardias. Bilbao: Artezblai S.L., 2008.

Sperber, Dan. El simbolismo en general. Traducido por J.M. García de la Mora. Barcelona: Editorial Anthropos, 1978.

Tolmacheva, Galina. Creadores del teatro moderno. Ciudad de México: Escenología A.C., 2011.

Vallejo, Patricio. Teatro y vida cotidiana. Quito: Universidad Andina Simón Bolívar, Sede Ecuador / Corporación Editora Nacional / Ediciones Abya Yala, 2003.

Watson, Ian. Hacia un tercer teatro. Traducido por Susana Epstein. Ciudad Real: Ñaque Editora, 2000. 